\title{
EFFECT OF THE COMBINED NOZZLE ORIENTATION AND TRUCK SPEED ON EFFICACY OF ULTRA-LOW-VOLUME SPRAY AGAINST CAGED AEDES ALBOPICTUS IN URBAN GAINESVILLE, FLORIDA $\dagger$
}

\author{
YONGXING JIANG', MUHAMMAD FAROOQ², JAMES CILEK³, \\ AND ALEC G. RICHARDSON ${ }^{3}$ \\ 'Department of Public Works, City of Gainesville Mosquito Control, \\ Gainesville, FL 32609
}

${ }^{2}$ Anastasia Mosquito Control District, St. Augustine, FL 32092

${ }^{3}$ Navy Entomology Center of Excellence, Jacksonville, FL 32212

Subiect Editor: Rui-De Xue

\begin{abstract}
A field study was conducted to evaluate the combined effect of nozzle orientation and vehicle travel speed on droplet dispersion and mosquito mortality of an adulticide applied from a truck mounted ULV sprayer in the City of Gainesville, Florida. Three multi-block areas with dense, medium, and sparse vegetation were selected for the study. Aqua-Reslin ${ }^{\circledast}$ was applied in each area in the following treatment combinations: a) horizontal nozzle at $24 \mathrm{~km} / \mathrm{h}$ travel speed, b) $45^{\circ}$ upward orientation (standard) at $16 \mathrm{~km} / \mathrm{h}$, and c) $22.5^{\circ}$ upward orientation at 24 $\mathrm{km} / \mathrm{h}$. Caged, three to five day old Aedes albopictus females were used in all evaluations. Spray deposition was determined at various locations inside each application area using Florida Latham Bonds droplet impingers. There was a significant difference in 24-h mortality among the 3 nozzle angle and speed treatment combinations, but not in the interaction between those combinations and application distance. The $22.5^{\circ}$ nozzle combination resulted in the greatest mosquito mortality $(88.3 \%)$ while the $45^{\circ}$ combination resulted in the least mortality $(63.1 \%)$. A significant difference in 24-h mortality among the 3 vegetation densities and application distances occurred with no significant interaction among these two parameters. The greatest Ae. albopictus mortality was recorded in the sparse $(91.4 \%)$ and the lowest in the medium vegetation area $(72.2 \%)$ at the maximum rate of $0.0015 \mathrm{lb}$./acre. Adulticide deposition was not significantly different among vegetation levels, but was significantly different among the distances and interactions of those parameters.
\end{abstract}

Key Words: Adulticide efficacy, Aqua-Reslin, London Fogger 18-20, permethrin, vegetation density

\section{INTRODUCTION}

Ground application of ultra-low-volume (ULV) adulticides has been the standard method to combat pestiferous and disease transmitting mosquitoes worldwide for more than 45 years (Bonds 2012). As a key component of Integrated Mosquito Management (IMM), ground application of ULV has been studied extensively, however, control efficacy has varied greatly. Mount (1998) has discussed a number of factors that could affect the control efficacy of ground applied ULV adulticides including droplet size, meteorology (e.g. wind speed and direction, temperature, relative humidity, atmospheric stability and turbulence), vegetation, and structural obstacles (such as homes, solid walls or board fences). Bonds (2012) further discussed the effectiveness of adulticide application timing and whether or not the aerosol plume actually contacted mosqui-

\footnotetext{
${ }^{\dagger}$ Mention of a trademark, vendor, or proprietary product does not constitute a guarantee or warranty of the product by the US Navy and does not imply its approval to the exclusion of other products that may also be suitable. The views expressed in this article are those of the author and do not necessarily reflect the official policy or position of the Department of the Navy, Department of Defense, nor the U.S. Government.
} 
toes directly. However, no reviews or studies have discussed or tested the potential effect of nozzle discharge direction on the effectiveness of ULV ground applications in controlling adult mosquitoes. The current common practice of ULV application in Florida, and elsewhere, is to orient the spray nozzle at an upward arc of $45^{\circ}$ (Teske et al. 2015). To date, no published data are available to support the fact that this angle is the optimal one in terms of control efficacy.

Jiang and Farooq (2016) compared the efficacy of truck mounted ULV sprayer nozzle discharge direction at $45^{\circ}$ upward and $0^{\circ}$ horizontal in urban Gainesville, Florida against caged Aedes aegypti (L.). Results indicated that a horizontally oriented nozzle outperformed a $45^{\circ}$ upward nozzle in three out of four field trials. Recently, Farooq et al. (2017) reported from an open field study that the greatest mortality of caged adult $A e$. aegypti occurred when the nozzle angle was positioned horizontally, followed by a $30^{\circ}$ downward angle, while a $45^{\circ}$ angle showed the least efficacy. The above two studies point out that nozzle discharge direction could have an actual impact on the efficacy of a ULV spray.

Mount (1998) believed that when an effective insecticide dose and appropriate atomization are maintained for a designated swath, dispersal speed (vehicle speed) is not a factor affecting efficacy. However, the most recent study reported by Farooq et al. (2018) showed that $32 \mathrm{~km} / \mathrm{h}$ travel speed provided the best ULV spray dispersal as indicated by complete mortality of caged female $A e$. aegypti up to $91 \mathrm{~m}$ from the spray line compared with 8 and $16 \mathrm{~km} / \mathrm{h}$. Farooq et al. (2018) further discussed that movement of a vehicle creates an air vortex behind it that strengthens with increasing travel speed. This vortex helps mix the spray with air, resulting in higher probability of droplets contacting flying insects. Moreover, the speed of the induced air increases with an increase in travel speed (Farooq et al. 2018). The induced air deflects the spray plume towards the ground and suppresses upward spray movement resulting in better efficacy. Therefore, the objective of this study was to evaluate the effectiveness of a combination of the best nozzle orientation and truck speed for ULV adulticide application against caged Ae. albopictus (Skuse) in an urban residential area of Gainesville, Florida.

\section{MATERIALS AND METHODS}

\section{Study sites}

Previous studies indicated that landscape and housing density have an impact on the effectiveness of ULV spray (Mount et al. 1968; Pant et al. 1971). In order to test the impacts, three communities, namely Ridgeview [ [ $2^{\circ} 41^{\prime} 02.7^{\prime \prime} \mathrm{N}, 82^{\circ} 20^{\prime} 54.7^{\prime \prime} \mathrm{W}$ ], Iron Wood [ $\left[2^{\circ} 41^{\prime} 48.3^{\prime \prime} \mathrm{N}, 82^{\circ} 18^{\prime} 16.8^{\prime \prime}\right.$ $\mathrm{W}]$, and Lamplighter $\left[2^{\circ} 40^{\prime} 33.7^{\prime \prime} \mathrm{N}, 82^{\circ}\right.$ $15^{\prime} 36.1 " \mathrm{~W}$ ] located in Gainesville, Florida were selected for the testing sites. Each community was classified as dense, medium and sparse based on visual estimation of vegetation cover, age of the houses and width of the street. The Ridgeview community was built in the 1960's that consisted of mixed dense vegetation of landscaped palms, ornamental plants, Southern live oaks, and pine trees. Houses were characteristically terraced with shared backyards along a two lane-street without sidewalks. Most front yards were covered with heavy ornamental plants such as holly, Indian hawthorn, and evergreen azaleas. The Iron Wood community was built in the late 1980's with a medium dense vegetation of low shrubs, Southern live oak, and palm trees. These terraced houses are mostly single-family detached homes with shared backyards, two lane-streets and sidewalks. Most of front yards are covered by turf grasses and flower beds. Lamplighter is a single or double-wide mobile home community built in the 1970s with very few shrubs and little to no vegetation present in the front or shared backyards.

\section{Mosquitoes}

Mosquitoes used in this study were obtained from an insecticide-susceptible USDA strain of Ae. albopictus, reared at Gainesville Mosquito Control headquarters at $26.6{ }^{\circ} \mathrm{C}$, $85 \pm 5 \%$ RH, and a photoperiod of 14:10 (L: 
D). Larvae were fed with a 3:2 mixture of bovine liver powder (MP Biomedicals, LLC, $\mathrm{OH}$ ) and brewer's yeast (MP Biomedicals, LLC, OH). Adult mosquitoes were supplied with $10 \%$ sugar water, and 3-5 days old nonblood-fed females were used in all evaluations.

\section{Test product}

Aqua-Reslin ${ }^{\circledR} \quad(20.0 \%$ permethrin $\mathrm{AI}$, $20 \%$ PBO, Bayer Environmental Science) a synergized permethrin water-based permethrin was used for this study. The formulation was diluted with water at the ratio of $1: 2$ and the flow rate is $142 \mathrm{ml} / \mathrm{min}$ which is the maximum rate of $0.0015 \mathrm{lb}$./acre.

\section{Field study}

Field studies were conducted following the methods of Farooq et al. (2017) with minor modifications. Briefly, Aqua-Reslin ${ }^{\circledR}$, mixed with a fluorescent dye (1, 3, 6, 8-pyrene tetra sulfonic acid tetra sodium salt, Spectra Colors Corporation, Kearny, NJ) at $8,000 \mathrm{ppm}$, was used. The spray mixture was applied with a truck-mounted ULV London Fogger 18-20 (London Foggers, Minneapo- lis, MN) at a flow rate of $142 \mathrm{ml} / \mathrm{min}$. This equipment produced spray droplets with a volume median diameter $\left(\mathrm{Dv}_{0.5}\right)$ of $15.9 \mathrm{mi}-$ crons and $\mathrm{D}_{\mathrm{v} 0.9}$ of 30.4 microns. Treatments included a) standard nozzle orientation $45^{\circ}$ upward at a travel speed of $16 \mathrm{~km} / \mathrm{h}\left(45^{\circ}\right.$ combination), b) $22.5^{\circ}$ upward at $24 \mathrm{~km} / \mathrm{h}$ (22.5 combination), and c) $0^{\circ}$ (horizontal) at $24 \mathrm{~km} / \mathrm{h}\left(0^{\circ}\right.$ combination $)$. Effectiveness of each application combination was assessed by determining Ae. albopictus mortality $24 \mathrm{~h}$ post-application, spray deposition quantification, and droplet size spectra.

Figure 1 illustrates the field layout, ULV spraying direction, and relative position of bioassay cages. Two rows of bioassay cages were placed at least $15 \mathrm{~m}$ apart, and up to $90 \mathrm{~m}$ perpendicular to the spray line. Each row contained six cages with 25 female $A e$. albopictus per cage, were positioned at 0,15 , $30,45,60$, and $90 \mathrm{~m}$ from the line of application. Alongside, and $1 \mathrm{~m}$ away from each treatment cage, a Florida Latham Bonds spinner (model 319; John W. Hock Company, Gainesville, FL) using two $3 \mathrm{~mm} \times 75 \mathrm{~mm}$ acrylic rods was deployed to collect sprays for assessing droplet size characterization and deposition. One of the 2 rods was used for

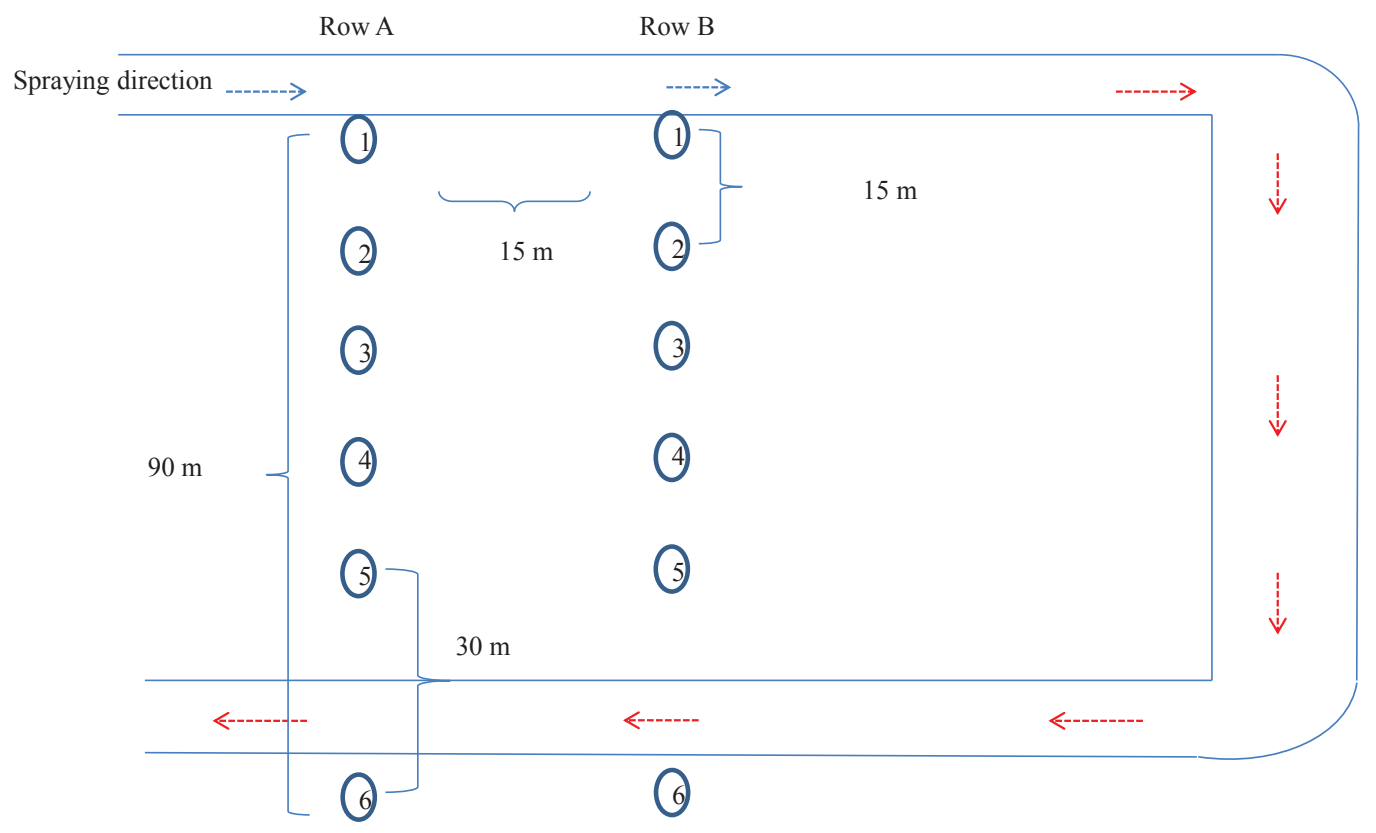

Figure 1. Field layout illustrating relative position of mosquito sentinel cages and spraying directions. 
droplet size and the other for quantification of adulticide deposition. Cages and spinners were suspended $1.5 \mathrm{~m}$ above ground. On the first day, both rows of samplers in three vegetation levels were randomly assigned to be sprayed with one of the three nozzle orientation and travel speed combinations to make 1 replication of all treatments. The 3 replications were made on 3 different days at least 2 weeks apart and treatments sequentially rotated. The same spray time sequence for sites on each day was maintained. Temperature, RH, wind speed, and wind direction were recorded $1.5 \mathrm{~m}$ above the ground.

Control cages were deployed well out and upwind of the spray zone and placed in the same environment for $15 \mathrm{~min}$, then collected before application. Spray cages and rods were placed in the field immediately before spraying. Cages were removed from all stations 15 min post-spray, supplied with $10 \%$ sugar solution, transferred to the laboratory, and maintained under normal room conditions until the $24 \mathrm{~h}$ mortality count was taken. Along with cages, spinner rods were also removed from the field. One rod from each location was preserved for measurement of droplets and the other stored in a pre-labeled, re-sealable plastic bag. All rods were then stored in a cool and dark environment and transported to the US Navy Entomology Center of Excellence laboratory where they were stored in a refrigerator for later droplet size measurements and determination of deposition.

Droplet size on rods was determined using the DropVision system (Leading Edge Associates Inc., Fletcher, NC) and droplet distribution parameters $\left(\mathrm{D}_{\mathrm{v} 0.1}, \mathrm{D}_{\mathrm{v} 0.5}\right.$, and $\mathrm{D}_{\mathrm{v} 0.9}$ ) were determined. The $\mathrm{D}_{\mathrm{v} 0.1}, \mathrm{D}_{\mathrm{v} 0.5}$, and $\mathrm{D}_{\mathrm{v} 0.9}$ are the droplet diameters $(\mu \mathrm{m})$ where 10,50 , and $90 \%$ of the spray volume is contained in droplets smaller than these diameters (ASTM Standard E1620, 2004). Adulticide deposition on rods was measured using the methods described by Farooq et al. (2009). Rods were washed inside a plastic bag using $25 \mathrm{ml}$ of deionized water. Fluorescence readings of the solution were determined using a spectrofluorophotometer (Shimadzu, Model RF5000U, Kyoto, Japan) and converted to the amount of dye on the slide using calibrations developed from a set of standardized fluorescence concentrations. The amount of dye in each sample was then divided by the effective sampling area of $63 \mathrm{~cm}^{2}$ to calculate dye deposition (ng/ $\mathrm{cm}^{2}$ ). Using the ratio of dye and active ingredient (AI) in the spray tank, deposition was converted to AI deposition $\left(\mathrm{ng} / \mathrm{cm}^{2}\right)$.

\section{Statistical analysis}

Statistical analysis was conducted with Intel® Visual Fortran Composer XE 2013. The Kolmogorov-Smirnov test (Smirnov 1939) showed that all datasets were non-normal and the Bartlett test (Bartlett 1937) showed non-homogeneity of variances. Therefore, mean $24 \mathrm{~h} \mathrm{Ae}$. albopictus mortality, adulticide deposition, and $\mathrm{Dv}_{0.5}$ data were subjected to a 3-way nonparametric Kruskal-Wallis analysis $(\alpha=0.05)$ that was used to assess differences among the nozzle combinations (i.e. $45^{\circ}$ upward at $16 \mathrm{~km} / \mathrm{h}, 22.5^{\circ}$ upward at $24 \mathrm{~km} / \mathrm{h}$, and $0^{\circ}$ horizontal at $24 \mathrm{~km} / \mathrm{h}$-factor 1 ), vegetation levels (dense, medium, and sparsefactor-2), and application distances (0, 15, $30,45,60$, and $90 \mathrm{~m}$-factor 3 ), as well as the interactions between the nozzle combination $\times$ vegetation, the nozzle combination $\times$ distance interaction, the vegetation type $\times$ distance interaction, and nozzle combination $\times$ vegetation type $\times$ distance interaction. Subsequent Tukey multiple-comparisons tests were conducted to identify those nozzle combination treatments that were significantly different from each other. Differences from all analyses were considered significant when $P<0.05$.

\section{RESULTS}

Effect of Nozzle Orientation and Speed on Mortality

There was a significant difference in 24-h mortality of caged Ae. albopictus among the 3 nozzle/speed combinations $(P=0.0096)$ and distances $(P=0.0212)$ but not the interaction between combination and distance $(P$ $=0.5863)$ (Figure 2$)$. The $22.5^{\circ}$ combination resulted in the greatest mortality $(88.3 \%)$ 


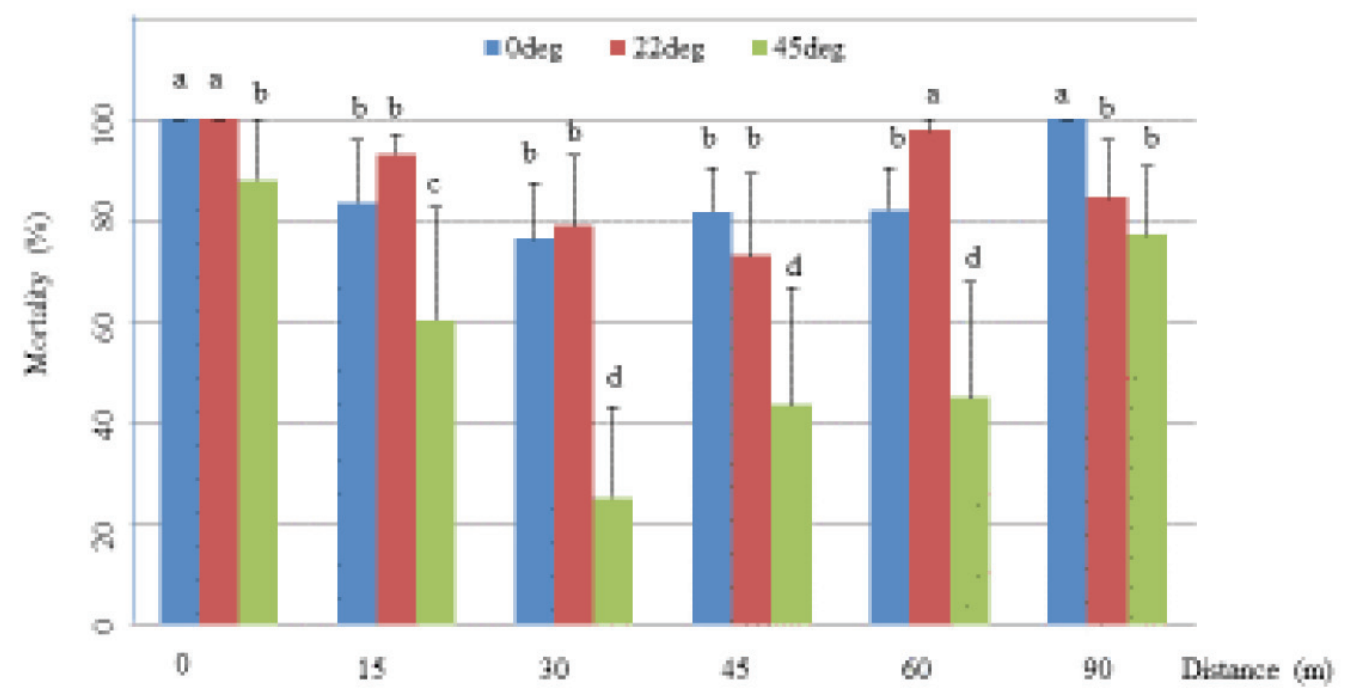

Figure 2. Comparison of 24-h mortality among the combinations of angle and speed and distances.

and $45^{\circ}$ combination resulted in the least mortality $(63.1 \%)$ (Table 1$)$. There was no significant difference between $22.5^{\circ}$ combination and $0^{\circ}$ combination in terms of 24-h mortality. At every distance, mortality from $45^{\circ}$ combination was significantly lower than $22.5^{\circ}$ and $0^{\circ}$ combinations. At distance $0 \mathrm{~m}$, $22.5^{\circ}$ and $0^{\circ}$ combinations resulted in $100 \%$ mortality; at distances of 15,30 , and $60 \mathrm{~m}$ the $22.5^{\circ}$ combination slightly outperformed $0^{\circ}$ whereas, at $45 \mathrm{~m}$, the $0^{\circ}$ combination slightly outperformed the $22.5^{\circ}$ combination but these differences were not significant (Figure 2).

Effect of Vegetation Density on Mosquito Mortality

There was a significant difference in 24-h mosquito mortality among the 3 vegetation levels $(P=0.0319)$ and distances $(P=0.0212)$ but no significant difference among the in- teractions of vegetation level and distance $(P=0.5863)$. The greatest mortality $(91.4 \%)$ was recorded in the sparse and the lowest in medium vegetation density $(72.2 \%)$ (Table 1). At $0 \mathrm{~m}$, no significant difference in $24-\mathrm{h}$ mortality among the three vegetation levels occurred. At $15 \mathrm{~m}$, Ae. albopictus mortality in the sparse vegetation community remained close to $100 \%$ but significantly lower mortality occurred in the medium and dense vegetation communities (Figure 3). At 30 $\mathrm{m}$, mortality in sparse vegetation areas decreased to $80 \%$ while in medium and dense locations mortality was further reduced to $60 \%$ and $40 \%$, respectively.

Effect of Nozzle Orientation and Travel Speed Combination on Adulticide Deposition

Adulticide deposition was not significantly affected by nozzle orientation and

Table 1. Mean mosquito mortality from nozzle angle combinations in different vegetation densities.

\begin{tabular}{lcccc}
\hline \hline & \multicolumn{3}{c}{ Mortality, \% (Mean \pm SD) from angle combinations } \\
\cline { 2 - 5 } Vegetation Density & $0^{\circ}$ & $22.5^{\circ}$ & $45^{\circ}$ & Average \\
\hline Dense & $74.9 \pm 23.2$ & $90.4 \pm 23.4$ & $59.7 \pm 45.0$ & $75.0 \pm 30.5$ \\
Medium & $86.6 \pm 15.3$ & $96.5 \pm 6.5$ & $33.5 \pm 41.9$ & $72.2 \pm 21.2$ \\
Sparse & $100.0 \pm 0.0$ & $78.1 \pm 29.7$ & $96.1 \pm 7.4$ & $91.4 \pm 12.4$ \\
Average & $87.2 \pm 12.8$ & $88.3 \pm 19.9$ & $63.1 \pm 31.4$ & $79.5 \pm 21.4$ \\
\hline
\end{tabular}




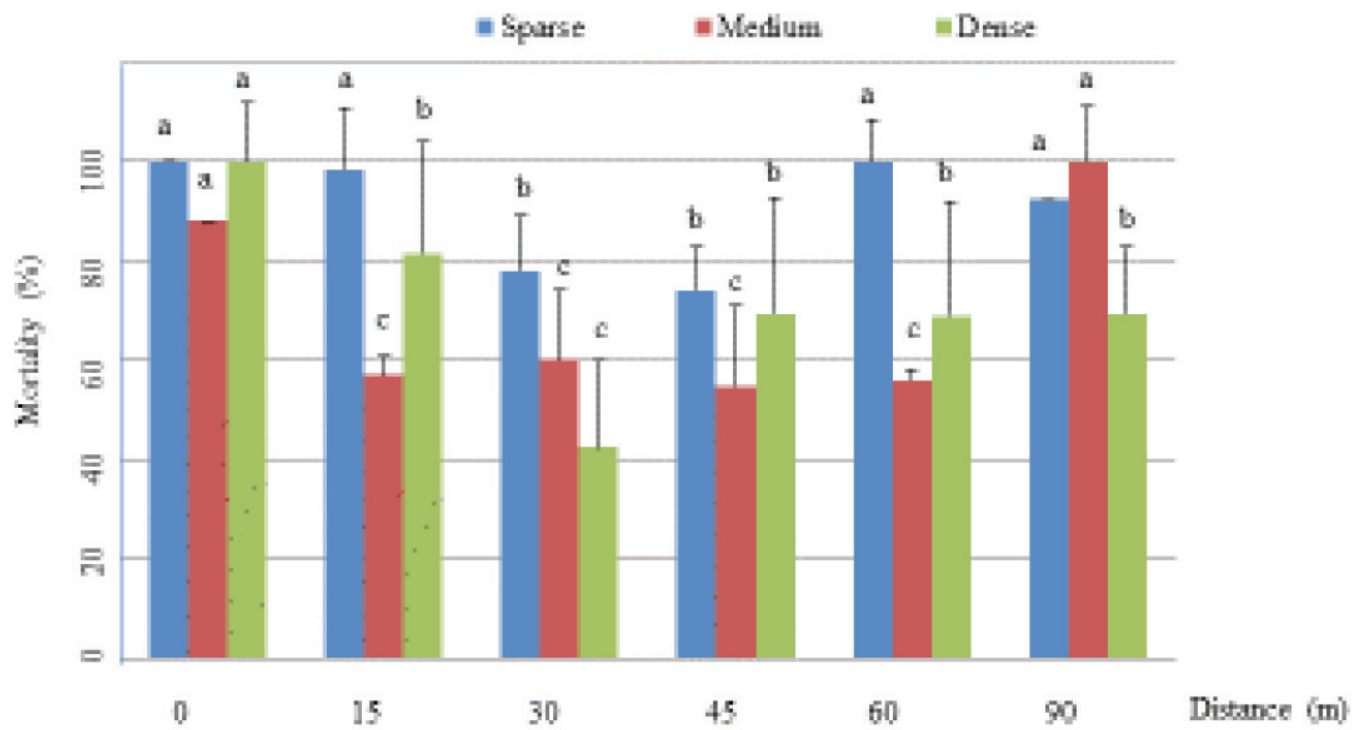

Figure 3. Comparison of 24-h mortality among the vegetation levels and distances.

travel speed combinations $(P=0.2066)$, or interaction of these combinations with distance $(P=0.2806)$. Deposition was significantly affected by application distance $(P<0.0001)$ (Figure 4$)$. Overall, $0^{\circ} \mathrm{com}-$ bination resulted in the greatest average deposition, followed by $22.5^{\circ}$ and $45^{\circ}$ combinations. At $0 \mathrm{~m}$, significantly higher deposition occurred from $0^{\circ}$ combination whereas at the remaining distances, there were no significant differences in deposition between nozzle/speed combinations (Figure 4).

Effect of Vegetation Density on Adulticide Deposition

Deposition on rods was not significantly different among the 3 vegetation densities

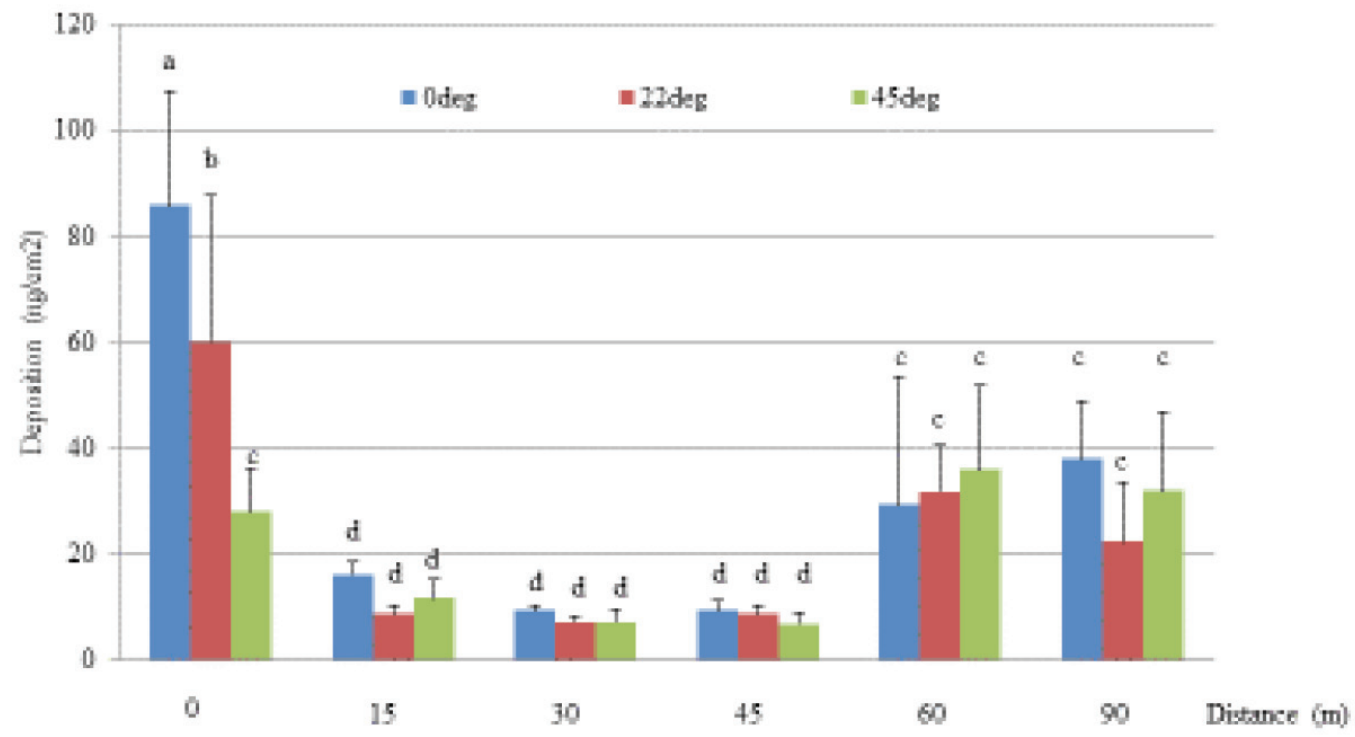

Figure 4. Comparison of deposition among the angel combinations and distances. 
among sampling distances $(P<0.0001)$ and interaction of vegetation density and distance $(P=0.0337)$. Generally, deposition was greatest $\left(27.5 \mathrm{ng} / \mathrm{cm}^{2}\right)$ for medium and lowest $\left(23.6 \mathrm{ng} / \mathrm{cm}^{2}\right)$ for sparse vegetation (Figure 5). Also, deposition was greatest at $0 \mathrm{~m}$ and lowest at $30 \mathrm{~m}$, and highest for $0^{\circ}$ combination at $0 \mathrm{~m}$ and lowest at $45^{\circ}$ combination at $30 \mathrm{~m}$ (Figure 4).

\section{DISCUSSION}

Farooq et al. (2017, 2018) demonstrated that nozzle orientation or travel speed alone resulted in a significant impact on adulticide efficacy in an open field. Overall, horizontal nozzle spraying with a truck mounted ULV sprayer achieved the greatest efficacy against adult Ae. aegypti, followed by a $30^{\circ}$ downward nozzle angle while a $45^{\circ}$ angle upward showed the least effectiveness (Farooq et al. 2017). Jiang and Farooq (2016) showed that a ULV nozzle oriented horizontally outperformed those upward at $45^{\circ}$ in three out of four field trials, although those differences were not statistically significant. In addition, Farooq et al. (2018) recently reported that a travel speed of $32 \mathrm{~km} / \mathrm{h}$ achieved the highest efficacy against caged Ae. aegypti followed by $16 \mathrm{~km} / \mathrm{h}$ and then $8 \mathrm{~km} / \mathrm{h}$. Our study found that a ULV nozzle oriented at $22.5^{\circ}$ at a travel speed of $24 \mathrm{~km} / \mathrm{h}$ resulted in the greatest mortality against Ae. albopictus whereas, the standard nozzle orientation of $45^{\circ}$ at speed of $16 \mathrm{~km} / \mathrm{h}$ (10 mph) resulted in the least mortality. These results confirmed that by changing nozzle orientation and travel speed together one can significantly improve adulticide efficacy. Farooq et al. (2017) explained that when spray nozzles are oriented at $45^{\circ}$ upward, most spray material remains above the mosquito fly zone, so no droplets $<40 \mu \mathrm{m}$ would descend to the space $1.4 \mathrm{~m}$ above ground (which is habitat for most humans and mosquitoes) before traveling $100 \mathrm{~m}$ in a horizontal direction. By setting the nozzle orientation lower than $45^{\circ}$ upward, enhanced mixing of spray into the air by the truck wake may have also resulted in an increase of spray efficacy. Likewise, improvement in application effectiveness with increased travel speed is due to the resultant combination of two physical phenomena. First, the induced air movement due to vehicle travel occurs in an opposite direction and increases with an increase in travel speed. The induced air deflects the spray plume towards the ground and suppresses upward

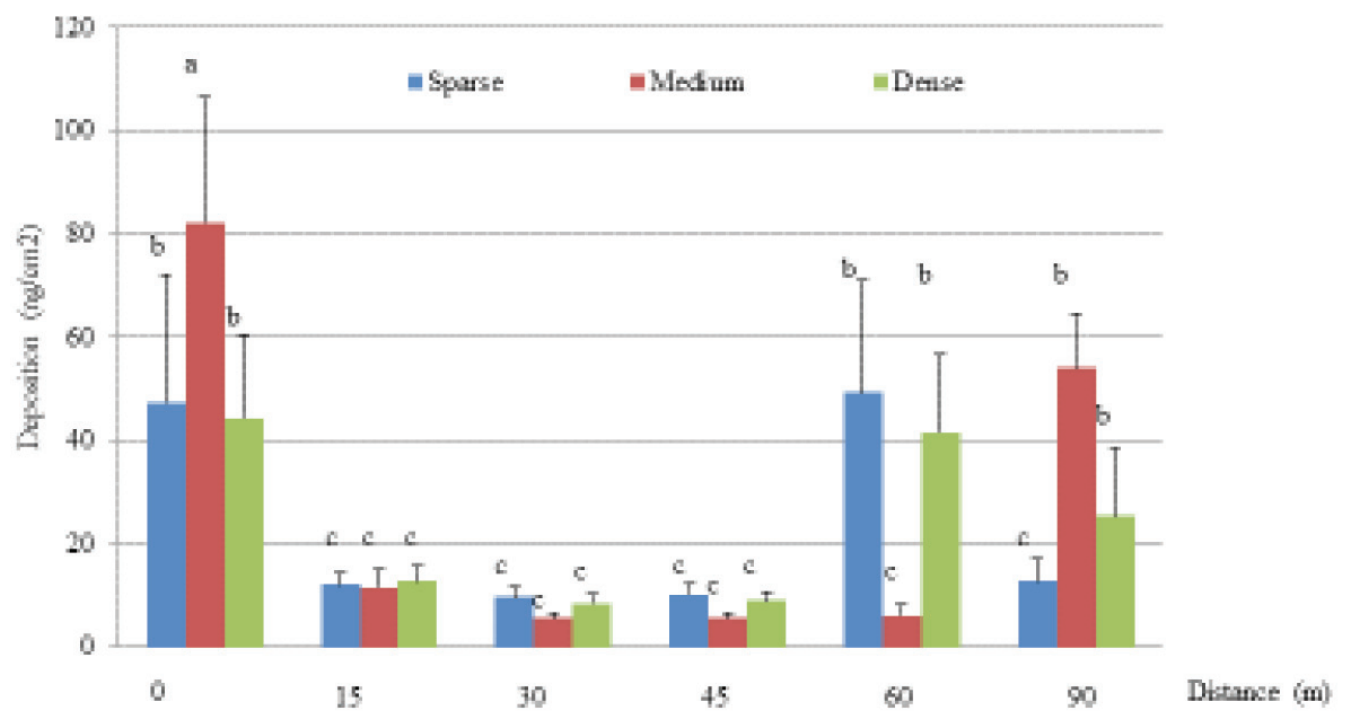

Figure 5. Comparison of deposition among the vegetation levels and distances. 
droplet movement resulting in better efficacy. Second, movement of a vehicle creates an air vortex behind it that strengthens with increasing travel speed. This vortex helps to better mix the spray with air, resulting in a higher probability of droplets contacting flying insects (Farooq et al. 2018). At an upward nozzle of $45^{\circ}$, the spray cloud is generally not expected to interact with the vortex behind the vehicle.

Vegetation and housing density is another factor that has a significant impact upon control effectiveness as reported by many authors. Taylor and Schoof (1971) obtained twice the level of kill for 3 species of mosquitoes exposed to $95 \%$ malathion aerosols in an open area compared with those exposed in moderately dense wooded areas. Andis et al. (1987) stated that the average mortality of caged $A e$. aegypti was $95.5 \%$ and $49 \%$ in open and sequestered locations, respectively. Linley and Jordan (1992) obtained greater percent kills of caged Culex quinquefasciatus Say exposed to aerosols of malathion, naled, and resmethrin plus piperonyl butoxide in open compared with vegetated terrain. Results from our study showed that $0^{\circ}$ and $22.5^{\circ}$ combinations resulted in 75 and $90 \%$ mortality of Ae. albopictus, respectively in dense vegetation, compared with $60 \%$ from the standard $45^{\circ}$ combination. Comparing our results with those reported by Taylor and Schoof (1971), Andis et al. (1987), and Linley and Jordan (1992) indicated that adjusting nozzle orientation increased mortality in vegetation.

In summary, significant improvement in performance of a ULV applied adulticide was achieved when the combination of an optimal nozzle orientation was paired with an increase in travel speed. Importantly, Farooq et al (2017) pointed out that this application optimization does not require a structural change, takes only a few minutes to accomplish, and has a significant impact on spray efficacy.

\section{ACKNOWLEDGMENTS}

This study was supported in part by a grant from the Deployed War-Fighter Pro- tection Research Program, funded by the US Department of Defense through the Armed Forces Pest Management Board. The authors thank Josh Weston and Jason Fajardo of the US Navy Entomology Center of Excellence, Jacksonville, FL, and Jarod Lloyd, Justin Baker, Cason Bartz and Karen St. Pierre of Gainesville Mosquito Control, Gainesville, FL, for their support during different parts of the study.

\section{REFERENCES CITED}

Andis MD, Sackett SR, Carroll MK, Bordes ES. 1987. Strategies for the emergency control of arboviral epidemics in New Orleans. J Am Mosq Control Assoc 3:125-130.

ASTM [American Society for Testing and Materials]. 2004, Standard E1620. Terminology relating to liquid particles and atomization. Annual Book of ASTM Standards. West Conshohocken, PA: ASTM International.

Bartlett MS. 1937. Properties of sufficiency and statistical tests. Proc Royal Statist Soc Ser A 160: 268-282.

Bonds JAS. 2012. Ultra-low-volume space sprays in mosquito control: a critical review. Med. Vet. Entomol. 26: 121-130.

Farooq M, Hoffmann WC, Walker TW, Smith VL, Robinson CA, Dunford JC, Sutherland IW. 2009. Samplers for evaluation and quantification of ultra-low volume space sprays. J Am Mosq Control Assoc 25:521524.

Farooq M, Fulcher A, Xue RD, Smith ML, Anderson JL, Richardson SR, Knapp JA. 2017. Effect of nozzle orientation on dispersion of Aqualuer 20-20 sprayed by a truck-mounted ultra-low-volume sprayer against caged Aedes aegypti. J Am Mosq Control Assoc 33: 209214.

Farooq M, Gibson-Corrado J, Knapp JA, Xue RD, Smith ML, Briley AKC, Richardson AR and Cilek J. 2018. Effect of travel speed on dispersion of Aqualuer 20-20 sprayed by a truck-mounted ultra-low-volume sprayer against caged Aedes aegypti. J Am Mosq Control Assoc 34: 70-74.

Jiang YX, Farooq M. 2016. $45^{\circ}$ or $0^{\circ}$ : Efficacy of ULV Sprayer Nozzle Discharge Direction in Urban Gainesville against caged Aedes aegypti. Abstract of 82th Annual meeting of American Mosquito Control Association, Savannah, GA.

Kruskal WH, Wallis WA. 1952. Use of ranks in one criterion analysis of variance. J Am Statist Assoc 47:583621.

Linley JR, Jordan S. 1992. Effects of ultra-low-volume and thermal fog malathion, Scourge and naled applied against caged adult Culicoides furens and Culex quinquefasciatus in open and vegetated terrain. $\mathrm{JAm}$ Mosq Control Assoc 8: 69-76.

Mount GA.1998. A critical review of ultralow-volume aerosols of insecticide applied with vehicle-mounted generators for adult mosquito control. J Am Mosq Control Assoc 14: 305-334.

Mount GA, Lofgren CS, Pierce NW, Husman CN. 1968. Ultra-low volume nonthermal aerosols of malathion 
Jiang et al.: Impact of nozzle orientation \& truck speed on Aedes albopictus

and naled for adult mosquito control. Mosq. News 28: 99-103.

Pant CP, mount GA, Jatanasen S, Mathis HL. 1971. Ultra-low-volume ground aerosols of technical malathion for the control of Aedes aegypti L. Bull. WHO 45: 805-817.

Smirnov NV. 1939. On the estimation of the discrepancy between empirical curves of distribution for two independent samples. Bull Moscow Univ Intern Ser (Math) 2:3-16.
Taylor RT, Schoof HF. 1971. The relative effectiveness of malathion thermal aerosols and ground-applied ULV against three species of mosquitoes. Mosq News 31: 346-349.

Teske ME, Thistle HW, Bonds AS. 2015. A technical review of Mulv-Disp, a recent mosquito ultra-low volume pesticide spray dispersion model. JAm Mosq Control Assoc 31: 262-270. 